\title{
A New Keynesian Perspective on the Great Recession
}

\author{
Peter N. Ireland* \\ Boston College and NBER
}

April 2010

\begin{abstract}
With an estimated New Keynesian model, this paper compares the "great recession" of 2007-09 to its two immediate predecessors in 1990-91 and 2001. The model attributes all three downturns to a similar mix of aggregate demand and supply disturbances. The most recent series of adverse shocks lasted longer and became more severe, however, prolonging and deepening the great recession. In addition, the zero lower bound on the nominal interest rate prevented monetary policy from stabilizing the US economy as it had previously; counterfactual simulations suggest that without this constraint, output would have recovered sooner and more quickly in 2009.
\end{abstract}

JEL: E32, E52.

*Please address correspondence to: Peter N. Ireland, Boston College, Department of Economics, 140 Commonwealth Avenue, Chestnut Hill, MA 02467-3859. Tel: (617) 552-3687. Fax: (617) 552-2308. Email: irelandp@bc.edu. http://www2.bc.edu/ irelandp. The opinions, findings, conclusions, and recommendations expressed herein are my own and do not reflect those of the National Bureau of Economic Research. 


\section{Introduction}

No matter what happens next, this seems safe to say: that the recession of 2007 through 2009 will always be remembered for its extreme severity. By many measures, in fact, it appears even now as the worst downturn the US economy has experienced since the Great Depression. It brought to an abrupt close the relatively tranquil period, lasting more than twenty years, that had become known as the "great moderation." And for all these reasons, it deserves a special name of its own: the "great recession" of 2007-09.

Indeed, the extreme severity of this great recession makes it tempting to argue that new theories are required to fully explain it. And given the prominence of the financial institutions whose solvency and liquidity problems grabbed and held the newspaper headlines as the broader economic crisis deepened, it is tempting to single out those solvency and liquidity problems as chief among the fundamental factors causing the recession itself.

But while, on the bright side, the extreme volatility in financial markets and across the economy as a whole surely has generated action in the data that will be useful in extending macroeconomic theory going forward, two sets of considerations suggest that it would be premature to abandon more familiar models just yet. First, banking failures and liquidity dry-ups seldom occur as totally exogenous events; this time around, they stemmed from problems in real estate markets that, themselves, undoubtedly reflect more basic macroeconomic fundamentals. Attempts to explain movements in one set of endogenous variables, like GDP and employment, by direct appeal to movements in another, like asset market valuations or interest rates, sometimes make for decent journalism but rarely produce satisfactory economic insights. Second, recessions have always been accompanied by an increase in bankruptcies among financial and nonfinancial firms alike, and one recent recession, in 1990-91, also featured systemic problems in banking that wiped out the savings and loan industry as a major segment of the US financial sector just as, today, the future of the investment banking industry has been thrown into doubt.

And so, in terms of its macroeconomics, is the great recession of 2007-09 really that dif- 
ferent from what came before? To answer this question, this paper examines and interprets recent data with the help of an estimated New Keynesian model, that is, within the same analytic framework that Lubik and Schorfheide (2004), Boivin and Giannoni (2006), Justiniano and Primiceri (2008), and Canova (2009), to mention just a small handful of related studies, use to consider various aspects of the great moderation. The focus here, however, lies entirely on the post-1983 period. Rather than comparing US business cycles before and during the great moderation, the objective here is to compare the great recession of 2007-09 to its two immediate predecessors: the milder recessions of 1990-91 and 2001.

The analysis suggests, in fact, that the 2007-09 recession has its origins in a combination of aggregate demand and supply disturbances that resembles quite closely the mix of shocks that set off the previous two downturns. The main difference is that for the most recent recession, the series of adverse shocks lasted much longer and became much larger; hence, the effects of that series of shocks lasted much longer and became much more severe as well. The analysis does point to another difference, however, relating to the zero lower bound on the nominal interest rate. This constraint on monetary policy became binding during 2007-09 recession, though not before. And the estimated model suggests that because of this constraint, monetary policy became quite restrictive, especially during 2009, contributing both to the length and severity of the downturn. By contrast, expansionary monetary policy helped, at least somewhat, in cushioning the US economy against the adverse shocks that hit during 1990-91 and 2001.

Altogether, these results deepen our understanding of recent US economy history. They point to systematic aspects of US monetary policy that might be reconsidered in light of that recent history. And they speak to the continued relevance of the New Keynesian model, perhaps not as providing the very last word on but certainly for offering up useful insights into, both macroeconomic analysis and monetary policy evaluation. 


\section{The Model}

\section{$2.1 \quad$ Overview}

The particular variant of the New Keynesian model used here takes its basic features from those developed by Ireland $(2004,2007)$. The modeling strategy thereby follows Canova's (2009) by using a small-scale model that focuses on three main equations: the New Keynesian IS curve, describing the optimizing behavior of a representative household, the New Keynesian Phillips curve, describing the optimizing behavior of monopolistically competitive firms that, in this case, face explicit costs of nominal price adjustment, and a version of the Taylor (1993) rule, describing how the central bank adjusts the short-term nominal interest rate in response to movements in output and inflation. Likewise, three variables take center stage in the empirical analysis: output, inflation, and the short-term nominal interest rate.

Relative to the simplest possible New Keynesian models, the framework used here gets enriched by introducing habit formation into the representative household's preferences, allowing for partially backward-looking behavior in the IS curve, and partial indexation into firms' price adjustment cost specification, allowing for partially backward-looking behavior in the Phillips curve. Again following Canova's (2009) strategy, the analysis here stops short of adding all of the extra features present in larger-scale New Keynesian models like Smets and Wouters' (2003), which would of course expand the model's internal dynamics still further but at the cost of complicating the macroeconomic story told by the theory and thereby

placing at risk the model's ability to distill useful information out of the action contained in the data.

The model economy, therefore, consists of a representative household, a representative finished goods-producing firm, a continuum of intermediate goods-producing firms indexed by $i \in[0,1]$, and a central bank. During each period $t=0,1,2, \ldots$, each intermediate goods-producing firm produces a distinct, perishable intermediate good. Hence, intermediate goods may also be indexed by $i \in[0,1]$, where firm $i$ produces good $i$. The model features 
enough symmetry, however, to allow the analysis to focus on the behavior of a representative intermediate goods-producing firm, identified by the generic index $i$. The activities of each agent, and their implications for the evolution of equilibrium prices and quantities, will now be described in turn.

\subsection{The Representative Household}

The representative household enters each period $t=0,1,2, \ldots$ with money $M_{t-1}$ and bonds $B_{t-1}$. At the beginning of period $t$, the household receives a lump-sum nominal transfer $T_{t}$ from the central bank. Next, the household's bonds mature, providing $B_{t-1}$ additional units of money. The household uses some of its money to purchase $B_{t}$ new bonds at the price of $1 / r_{t}$ units of money per bond, where $r_{t}$ denotes the gross nominal interest rate between $t$ and $t+1$.

During period $t$, the household supplies a total of $h_{t}$ units of labor to the various intermediate goods-producing firms. The household gets paid at the nominal wage rate $W_{t}$, earning $W_{t} h_{t}$ in total labor income during the period. Also during the period, the household consumes $C_{t}$ units of the finished good, purchased at the nominal price $P_{t}$ from the representative finished goods-producing firm.

At the end of period $t$, the household receives nominal dividend payments totaling $D_{t}$, representing the profits earned by the various intermediate goods-producing firms. The household then carries $M_{t}$ units of money into period $t+1$, where its budget constraint dictates that

$$
\frac{M_{t-1}+T_{t}+B_{t-1}+W_{t} h_{t}+D_{t}}{P_{t}} \geq C_{t}+\frac{M_{t}+B_{t} / r_{t}}{P_{t}}
$$

for all $t=0,1,2, \ldots$

The household's preferences are described by the expected utility function

$$
E_{0} \sum_{t=0}^{\infty} \beta^{t} a_{t}\left[\ln \left(C_{t}-\gamma C_{t-1}\right)+\ln \left(M_{t} / P_{t}\right)-h_{t}\right]
$$


where both the discount factor and the habit formation parameter lie between zero and one: $0<\beta<1$ and $0 \leq \gamma<1$. The preference shock $a_{t}$ follows the stationary autoregressive process

$$
\ln \left(a_{t}\right)=\rho_{a} \ln \left(a_{t-1}\right)+\varepsilon_{a t}
$$

for all $t=0,1,2, \ldots$, with $0 \leq \rho_{a}<1$, where the serially uncorrelated innovation $\varepsilon_{a t}$ is normally distributed with mean zero and standard deviation $\sigma_{a}$. Utility is additively separable across consumption, real money balances, and hours worked so as to imply a conventional specification for the model's IS curve that, in particular, does not include additional terms involving real balances or employment. Given this additive separability, the logarithmic specification over consumption is needed, as shown by King, Plosser, and Rebelo (1988), for the model to be consistent with balanced growth. And, as noted above, habit formation is introduced into preferences to allow for partially backward-looking behavior in consumption.

Thus, the household chooses $C_{t}, h_{t}, B_{t}$, and $M_{t}$ for all $t=0,1,2, \ldots$ to maximize its utility function subject to the budget constraint (1) for all $t=0,1,2, \ldots$. The first-order conditions for this problem can be written as

$$
\begin{gathered}
\Lambda_{t}=\frac{a_{t}}{C_{t}-\gamma C_{t-1}}-\beta \gamma E_{t}\left(\frac{a_{t+1}}{C_{t+1}-\gamma C_{t}}\right), \\
a_{t}=\Lambda_{t}\left(W_{t} / P_{t}\right), \\
\Lambda_{t}=\beta r_{t} E_{t}\left(\Lambda_{t+1} / \pi_{t+1}\right), \\
M_{t} / P_{t}=\left(a_{t} / \Lambda_{t}\right)\left[r_{t} /\left(r_{t}-1\right)\right]
\end{gathered}
$$

and (1) with equality for all $t=0,1,2, \ldots$, where $\Lambda_{t}$ denotes the nonnegative Lagrange multiplier on the budget constraint for period $t$ and $\pi_{t}=P_{t} / P_{t-1}$ denotes the gross inflation rate between $t$ and $t+1$. 


\subsection{The Representative Finished Goods-Producing Firm}

During each period $t=0,1,2, \ldots$, the representative finished goods-producing firm uses $Y_{t}(i)$ units of each intermediate good $i \in[0,1]$, purchased at the nominal price $P_{t}(i)$, to manufacture $Y_{t}$ units of the finished good according to the constant-returns-to-scale technology described by

$$
\left[\int_{0}^{1} Y_{t}(i)^{\left(\theta_{t}-1\right) / \theta_{t}} \mathrm{~d} i\right]^{\theta_{t} /\left(\theta_{t}-1\right)} \geq Y_{t}
$$

where, in equilibrium, $\theta_{t}$ translates into a random shock to the intermediate goods-producing firms' desired markup of price over marginal cost and therefore acts like a cost-push shock of the kind introduced into the New Keynesian model by Clarida, Gali, and Gertler (1999). Here, this markup shock follows the stationary autoregressive process

$$
\ln \left(\theta_{t}\right)=\left(1-\rho_{\theta}\right) \ln (\theta)+\rho_{\theta} \ln \left(\theta_{t-1}\right)+\varepsilon_{\theta t},
$$

for all $t=0,1,2, \ldots$, with $0 \leq \rho_{\theta}<1$ and $\theta>1$, where the serially uncorrelated innovation $\varepsilon_{\theta t}$ is normally distributed with mean zero and standard deviation $\sigma_{\theta}$.

Thus, during each period $t=0,1,2, \ldots$, the finished goods-producing firm chooses $Y_{t}(i)$ for all $i \in[0,1]$ to maximize its profits, which are given by

$$
P_{t}\left[\int_{0}^{1} Y_{t}(i)^{\left(\theta_{t}-1\right) / \theta_{t}} \mathrm{~d} i\right]^{\theta_{t} /\left(\theta_{t}-1\right)}-\int_{0}^{1} P_{t}(i) Y_{t}(i) \mathrm{d} i .
$$

The first-order conditions for this problem are

$$
Y_{t}(i)=\left[P_{t}(i) / P_{t}\right]^{-\theta_{t}} Y_{t}
$$

for all $i \in[0,1]$ and $t=0,1,2, \ldots$. Competition then drives the finished-goods producing 
firm's profits to zero in equilibrium, determining $P_{t}$ as

$$
P_{t}=\left[\int_{0}^{1} P_{t}(i)^{1-\theta_{t}} \mathrm{~d} i\right]^{1 /\left(1-\theta_{t}\right)}
$$

for all $t=0,1,2, \ldots$

\subsection{The Representative Intermediate Goods-Producing Firm}

During each period $t=0,1,2, \ldots$, the representative intermediate goods-producing firm hires $h_{t}(i)$ units of labor from the representative household to manufacture $Y_{t}(i)$ units of intermediate good $i$ according to the constant-returns-to-scale technology described by

$$
Z_{t} h_{t}(i) \geq Y_{t}(i)
$$

The aggregate technology shock $Z_{t}$ follows a random walk with drift:

$$
\ln \left(Z_{t}\right)=\ln (z)+\ln \left(Z_{t-1}\right)+\varepsilon_{z t}
$$

for all $t=0,1,2, \ldots$, with $z>1$ and where the serially uncorrelated innovation $\varepsilon_{z t}$ is normally distributed with mean zero and standard deviation $\sigma_{z}$.

Since the intermediate goods substitute imperfectly for one another in producing the finished good, the representative intermediate goods-producing firm sells its output in a monopolistically competitive market: during period $t$, the firm sets its nominal price $P_{t}(i)$, subject to the requirement that it satisfy the representative finished goods-producing firm's demand at that price. And, following Rotemberg (1982), the intermediate goods-producing firm faces a quadratic cost of adjusting its nominal price between periods, measured in terms of the finished good and given by

$$
\frac{\phi}{2}\left[\frac{P_{t}(i)}{\pi_{t-1}^{\alpha} \pi^{1-\alpha} P_{t-1}(i)}-1\right]^{2} Y_{t}
$$


where $\phi \geq 0$ governs the magnitude of the price adjustment cost, $\alpha$ is a parameter that lies between zero and one, with $0 \leq \alpha \leq 1$, and $\pi$ denotes the average, or steady-state, rate of inflation. According to this specification, the extent to which price setting is backward or forward-looking depends on the magnitude of the parameter $\alpha$. When, in particular, $\alpha=0$, then price setting is purely forward-looking in the sense that there is no indexation of prices to past inflation rates. When, on the other hand, $\alpha=1$, then price setting is purely backward-looking, in the sense that there is full indexation of prices to the previous period's inflation rate.

In any case, the cost of price adjustment makes the intermediate goods-producing firm's problem dynamic: it chooses $P_{t}(i)$ for all $t=0,1,2, \ldots$ to maximize its total real market value, proportional to

$$
E_{0} \sum_{t=0}^{\infty} \beta^{t} \Lambda_{t}\left[D_{t}(i) / P_{t}\right]
$$

where $\beta^{t} \Lambda_{t}$ measures the marginal utility value to the representative household of an additional unit of real profits received in the form of dividends during period $t$ and where

$$
\frac{D_{t}(i)}{P_{t}}=\left[\frac{P_{t}(i)}{P_{t}}\right]^{1-\theta_{t}} Y_{t}-\left[\frac{P_{t}(i)}{P_{t}}\right]^{-\theta_{t}}\left(\frac{W_{t} Y_{t}}{P_{t} Z_{t}}\right)-\frac{\phi}{2}\left[\frac{P_{t}(i)}{\pi_{t-1}^{\alpha} \pi^{1-\alpha} P_{t-1}(i)}-1\right]^{2} Y_{t}
$$

measures the firm's real profits during the same period $t$. The first-order conditions for this problem are

$$
\begin{aligned}
0= & \left(1-\theta_{t}\right)\left[\frac{P_{t}(i)}{P_{t}}\right]^{-\theta_{t}}+\theta_{t}\left[\frac{P_{t}(i)}{P_{t}}\right]^{-\theta_{t}-1}\left(\frac{W_{t}}{P_{t} Z_{t}}\right) \\
& -\phi\left[\frac{P_{t}(i)}{\pi_{t-1}^{\alpha} \pi^{1-\alpha} P_{t-1}(i)}-1\right]\left[\frac{P_{t}(i)}{\pi_{t-1}^{\alpha} \pi^{1-\alpha} P_{t-1}(i)}\right] \\
& +\beta \phi E_{t}\left\{\left(\frac{\Lambda_{t+1}}{\Lambda_{t}}\right)\left[\frac{P_{t+1}(i)}{\pi_{t}^{\alpha} \pi^{1-\alpha} P_{t}(i)}-1\right]\left[\frac{P_{t+1}(i)}{\pi_{t}^{\alpha} \pi^{1-\alpha} P_{t}(i)}\right]\left[\frac{P_{t} Y_{t+1}}{P_{t}(i) Y_{t}}\right]\right\}
\end{aligned}
$$

and (8) with equality for all $t=0,1,2, \ldots$ 


\subsection{The Central Bank}

The central bank conducts monetary policy according to a variant of the Taylor (1993) rule

$$
\ln \left(r_{t}\right)-\ln \left(r_{t-1}\right)=\rho_{\pi} \ln \left(\pi_{t} / \pi\right)+\rho_{g} \ln \left(g_{t} / g\right)+\varepsilon_{r t}
$$

according to which it raises or lowers the short-term nominal interest rate whenever inflation $\pi_{t}$ and output growth

$$
g_{t}=Y_{t} / Y_{t-1}
$$

rise above or fall below their average, or steady-state, values $\pi$ and $g$. When implementing the policy rule (12), the central bank must choose the response coefficients $\rho_{\pi}>0$ and $\rho_{g} \geq 0$ in order to guarantee the existence of a unique rational expectations equilibrium; the central bank must also choose its long-run target $\pi$ for inflation. The serially uncorrelated monetary policy shock $\varepsilon_{r t}$ is normally distributed with mean zero and standard deviation $\sigma_{r}$.

\subsection{Symmetric Equilibrium}

In a symmetric equilibrium, all intermediate goods-producing firms make identical decisions, so that $Y_{t}(i)=Y_{t}, h_{t}(i)=h_{t}, D_{t}(i)=D_{t}$, and $P_{t}(i)=P_{t}$ for all $i \in[0,1]$ and $t=0,1,2, \ldots$ In addition, the market-clearing conditions $M_{t}=M_{t-1}+T_{t}$ for money and $B_{t}=B_{t-1}=0$ for bonds must hold for all $t=0,1,2, \ldots$. After imposing these equilibrium conditions and using (4), (6), (8), and (10) to solve out for $W_{t}, M_{t}, h_{t}$, and $D_{t}$, the remaining nine equations (1)-(3), (5), (7), (9), and (11)-(13) form a system determining the equilibrium behavior of the nine variables $Y_{t}, C_{t}, \pi_{t}, r_{t}, g_{t}, \Lambda_{t}, a_{t}, \theta_{t}$, and $Z_{t}$. A few of the real variables in this system inherit unit roots from the random walk (9) in the technology shock. However, the transformed variables $y_{t}=Y_{t} / Z_{t}, c_{t}=C_{t} / Z_{t}, \lambda_{t}=Z_{t} \Lambda_{t}$, and $z_{t}=Z_{t} / Z_{t-1}$ remain stationary, and the system can be rewritten in terms of these stationary variables.

The transformed system implies that in the absence of shocks, the economy converges 
to a steady-state growth path, along which all of the stationary variables are constant, with $y_{t}=y, c_{t}=c, \pi_{t}=\pi, r_{t}=r, g_{t}=g, \lambda_{t}=\lambda, a_{t}=a, \theta_{t}=\theta$, and $z_{t}=z$ for all $t=0,1,2, \ldots$ The transformed system can therefore be log-linearized around its steady state in order to describe how the economy responds to shocks. Let $\hat{y}_{t}=\ln \left(y_{t} / y\right), \hat{c}_{t}=\ln \left(c_{t} / c\right), \hat{\pi}_{t}=\ln \left(\pi_{t} / \pi\right)$, $\hat{r}_{t}=\ln \left(r_{t} / r\right), \hat{g}_{t}=\ln \left(g_{t} / g\right), \hat{\lambda}_{t}=\ln \left(\lambda_{t} / \lambda\right), \hat{a}_{t}=\ln \left(a_{t} / a\right), \hat{\theta}_{t}=\ln \left(\theta_{t} / \theta\right)$, and $\hat{z}_{t}=\ln \left(z_{t} / z\right)$ denote the percentage deviation of each stationary variable from its steady-state level. A first-order Taylor approximation to (1) reveals that $\hat{c}=\hat{y}$; since price adjustment costs are of second order according to the quadratic specification, consumption and output are equal to a first-order approximation. First-order approximations to the remaining eight equations then imply

$$
\begin{gathered}
\hat{a}_{t}=\rho_{a} \hat{a}_{t-1}+\varepsilon_{a t}, \\
(z-\beta \gamma)(z-\gamma) \hat{\lambda}_{t}=\gamma z \hat{y}_{t-1}-\left(z^{2}+\beta \gamma^{2}\right) \hat{y}_{t}+\beta \gamma z E_{t} \hat{y}_{t+1}+\left(z-\beta \gamma \rho_{a}\right)(z-\gamma) \hat{a}_{t}-\gamma z \hat{z}_{t}, \\
\hat{\lambda}_{t}=\hat{r}_{t}+E_{t} \hat{\lambda}_{t+1}-E_{t} \hat{\pi}_{t+1}, \\
\hat{e}_{t}=\rho_{e} \hat{e}_{t-1}+\varepsilon_{e t}, \\
\hat{z}_{t}=\varepsilon_{z t}, \\
(1+\beta \alpha) \hat{\pi}_{t}=\alpha \hat{\pi}_{t-1}+\beta E_{t} \hat{\pi}_{t+1}-\psi \hat{\lambda}_{t}+\psi \hat{a}_{t}+\hat{e}_{t}, \\
\hat{r}_{t}=\hat{r}_{t-1}+\rho_{\pi} \hat{\pi}_{t}+\rho_{g} \hat{g}_{t}+\varepsilon_{r t},
\end{gathered}
$$

and

$$
\hat{g}_{t}=\hat{y}_{t}-\hat{y}_{t-1}+\hat{z}_{t}
$$

for all $t=0,1,2, \ldots$ where, in (17) and (19), the cost-push shock $\hat{\theta}_{t}$ has been renormalized as $\hat{e}_{t}=-(1 / \phi) \hat{\theta}_{t}$ and the new parameters $\rho_{e}$ and $\psi$ have been defined as $\rho_{e}=\rho_{\theta}$ and $\psi=(\theta-1) / \phi$ so that $\varepsilon_{e t}$ is normally distributed with mean zero and standard deviation $\sigma_{e}=\sigma_{\theta} / \phi$

Within the linearized system, (15) defines the marginal utility of consumption in terms of 
past, present, and expected future output in this model with habit formation in preferences. In light of this definition, (16), becomes a version of the New Keynesian IS curve, linking past, present, and expected future output to the real interest rate. Equation (19) depicts a version of a New Keynesian Phillips curve, with partially backward and forward-looking components introduced through the indexation parameter $\alpha$; the equation indicates that in this specification, $\hat{a}_{t}-\hat{\lambda}_{t}$ measures the real marginal cost of production and the renormalized cost-push shock $\hat{e}_{t}$ impacts directly on inflation. Equation (20) simply rewrites the Taylor rule, (21) defines the growth rate of output, and (14), (17), and (18) repeat the log-linear laws of motion for the preference, cost-push, and technology shocks.

\section{Results}

The solution to the eight-equation system (14)-(21), derived using methods outlined by Blanchard and Kahn (1980) and Klein (2000), links the behavior of three observable, stationary variables - the output growth rate, the inflation rate, and the short-term nominal interest rate - to a vector of unobserved state variables that includes the model's four exogenous shocks. Conveniently, this solution can be written in the form of a state-space econometric model, allowing the Kalman filtering and smoothing algorithms outlined by Hamilton (1994, Ch.13) and extended by Kohn and Ansley (1983) to accommodate cases like this one where the state vector's covariance matrix turns out to be singular (here, because of the presence of lagged endogenous variables in the state vector) to be used to obtain maximum likelihood estimates of the model's structural parameters and to draw inferences about the behavior of the model's structural disturbances.

Here, this empirical exercise uses quarterly US data running from 1983:1 through 2009:4. The starting point comes after the sharp disinflationary episode that followed the appointment of Paul Volcker as Chairman of the Federal Reserve Board in 1979. Therefore, whereas previous studies including Clarida, Gali and Gertler (2000), Lubik and Schorfheide (2004), 
Boivin and Giannoni (2006), Justiniano and Primiceri (2008), and Canova (2009) focus on the regime change in Federal Reserve policy that occurred when Volcker assumed office and that may have contributed to the great moderation that followed, the analysis here centers on the period of the great moderation itself as well as the great recession of 2007-09 that brought the great moderation to its abrupt end.

In these data, output growth gets measured by quarter-to-quarter changes in the natural logarithm of real GDP in chained 2005 dollars, converted to per-capita terms using the civilian noninstitutional population ages 16 and over. The inflation rate gets measured by quarter-to-quarter changes in the natural logarithm of the GDP implicit price deflator. And the short-term nominal interest rate gets measured by quarterly averages of daily readings on the three-month US Treasury bill rate, converted from an annualized yield on a discount basis to a quarterly yield to maturity in order to bring the figures from the data in line with the corresponding variable as it appears in the theoretical model. By convention, the figures for real GDP and the deflator are seasonally adjusted; the figures for the population and the interest rate are not. All data come from the Federal Reserve Bank of St. Louis' FRED database.

The theoretical model has 14 structural parameters describing tastes, technologies, and Federal Reserve policy: $z, \pi, \beta, \gamma, \alpha, \psi, \rho_{\pi}, \rho_{g}, \rho_{a}, \rho_{e}, \sigma_{a}, \sigma_{e}, \sigma_{z}$, and $\sigma_{r}$. Since the steady-state values of output growth, inflation, and the short-term interest rate in the model are given by $z=g, \pi$, and $r=z \pi / \beta$, values $z=1.0046, \pi=1.0062$, and $\beta=0.9987$ fixed prior to estimation work to match the average annualized growth rate of real GDP per capita (1.85 percent), the average annualized inflation rate (2.50 percent), and the average annualized three-month Treasury bill rate (4.93 percent) in the data with the corresponding steady-state values in the model; in effect, this strategy estimates the other parameters using de-meaned data. Also, preliminary attempts to estimate the model led consistently to very small values of the Phillips-curve parameter $\psi$, corresponding to very large costs of nominal price adjustment. Hence, the value $\psi=0.10$ is also fixed prior to estimation; as explained in 
Ireland $(2004,2007)$, this setting for $\psi$ can be interpreted based on the fact that it implies an amount of sluggishness in nominal goods prices equivalent to what is produced by the alternative specification in which price-setting takes place in a staggered fashion following Calvo (1983) when each individual good's price remains fixed, on average, for 3.7 quarters, that is, for a bit less than one year.

Table 1 displays the maximum likelihood estimates of the model's ten remaining structural parameters. The estimates $\gamma=0.3904$ and $\alpha=0.0000$ indicate that for the 1983-2009 sample, the US data prefer a version of the model with a considerable amount of backwardlooking behavior in consumption but completely forward-looking behavior in price setting. The estimates $\rho_{\pi}=0.4153$ and $\rho_{g}=0.1270$ imply that monetary policy works to stabilize both inflation and output, though the policy response to the nominal variable is stronger. Finally, the estimates $\rho_{a}=0.9797$ and $\rho_{e}=0.0000$ make preference shocks highly persistent but leave cost-push shocks serially uncorrelated.

The standard errors, also reported in table 1, come from a parametric bootstrapping procedure based on Efron and Tibshirani's (1993, Ch.6), according to which the estimated model gets used to generate 1000 samples of artificial data on output growth, inflation, and the interest rate, each of the same length as the actual set of US data. Then, these artificial samples get used to re-estimate the model 1000 times, and the standard errors in table 1 get computed as the standard deviations of the individual parameter estimates across the 1000 replications.

Most notably, the standard errors reveal that while there is some uncertainty about the true degree of backward-looking behavior in consumption, the data speak rather definitively about the lack of backward-looking behavior in price setting, with essentially all of the bootstrapped replications pushing the estimate of the price indexation parameter $\alpha$ up against its lower bound of zero. The standard errors associated with $\rho_{\pi}$ and $\rho_{g}$ are of roughly equal magnitudes, implying that the monetary policy response to inflation is more important statistically as well as economically. And with the exception of $\sigma_{a}$, the standard deviation of the 
innovation to the preference shock, the parameters describing the persistence and volatility of the model's exogenous disturbances are estimated quite precisely too.

The New Keyensian theory outlined above works to identify structural disturbances in the data based on the dynamic effects that they have on the model's observable variables: output growth, inflation, and the nominal interest rate. Figure 1 illustrates these effects by tracing out the impulse responses of each variable to each shock. To facilitate their interpretation, the graphs express output in levels and inflation and interest rates in annualized terms.

In particular, the graphs in figure 1 show that whole both the preference and monetary policy shocks act like demand-side disturbances, moving output and inflation in the same direction, the preference shock associates an expansion in output with a rising nominal interest rate, whereas the monetary policy shock associates an increasing interest rate with a disinflationary contraction. The cost-push and technology shocks, meanwhile, both act as supply-side disturbances, moving output and inflation in opposite directions. However, the random walk specification (9) allows the technology shock alone to produce a permanent shift in the level of output. Moveover, the impulse responses show that the cost-push shock impacts more strongly on inflation than on output growth; therefore, under the estimated Taylor rule, an adverse cost-push shock calls forth a monetary policy tightening, that is, an increase in the short-term nominal interest rate.

Table 2 foreshadows many of the additional results that follow by decomposing forecast error variances in the three observable, stationary variables at various horizons into components attributable to the model's four exogenous shocks. Panel A shows that movements in output growth are driven primarily by a combination of preference and technology shocks, with monetary policy shocks playing a smaller but still nonnegligible role. Panel B indicates that movements in inflation, by contrast, are driven in more or less equal measures by all four shocks, while panel $\mathrm{C}$ attributes the bulk of all interest rate movements to preference shocks, except at higher frequencies where monetary policy disturbances also play a key role.

The numbers in table 2 reflect movements in output growth occurring throughout the 
post-1983 sample period, during recoveries and expansions as well as recessions. To identify the fundamental causes of the great recession of 2007-09 as well as the two recessions in 1990-91 and 2001 that preceded it, table 3 reports estimates of the individual shocks occurring during and immediately after those recessionary periods. These estimates of the shocks are smoothed, that is, they rely on information contained in the full sample of data. Important to keep in mind when interpreting the numbers in table 3 is the fact that while positive innovations $\varepsilon_{a t}$ and $\varepsilon_{z t}$ to the preference and technology shocks are expansionary, positive cost-push and monetary policy innovations $\varepsilon_{e t}$ and $\varepsilon_{r t}$ lead, according to the impulse responses shown earlier, to declines in output. And to help make clear exactly what constitutes a "large" shock, the maximum likelihood estimates of the standard deviations of each of these four innovations, shown before in table 1, are reproduced in panel D at the bottom of table 3 .

Panel A of table 3 indicates that adverse preference and technology shocks hit the US economy simultaneously at the beginning of the 1990-91 recession. The cost-push shocks remained small throughout this period. And the monetary policy shocks were largely favorable, suggesting that expansionary Federal Reserve policy helped offset at least some of the effects of the adverse preference and technology shocks on output.

Figure 2 leads to the same conclusions in a different way, by comparing the actual path for output, shown by the dashed line as percentage changes from the level reached at the previous cyclical peak, with counterfactual paths, expressed in similar terms by the solid lines, generated when all but one of the structural shocks is "turned off" so as to allow each single shock to operate in isolation. In particular, the graph in the lower left-hand panel of figure 2 reveals that technology shocks by themselves account for a large fraction of the output lost during the 1990-91 recession. Preference shocks, with effects illustrated in the upper left-hand panel, contributed noticeably to the downturn as well. And the lower righthand panel confirms that the expansionary monetary policy shocks during this period would have worked, by themselves, to generate faster output growth. 
Panel B of table 3 and the graphs in figure 3 tell a broadly similar story for the 2001 recession. According to the estimated model, a combination of adverse preference and technology shocks caused this recession too, with preference shocks apparently playing a slightly larger role and technology shocks a correspondingly smaller role than before, As in 199091, cost-push shocks contribute very little to output movements in 2001, though a series of expansionary monetary policy shocks helped to at least partly offset the decline in output caused by the preference and technology shocks.

Interestingly, according to panel $\mathrm{C}$ of table 3 and the graphs in figure 4 , the great recession began in late 2007 and early 2008 with a series of adverse preference and technology shocks in roughly the same mix and of roughly the same magnitude as those that hit the US at the onset of the previous two recessions. Likewise in late 2007 and early 2008, just as before, expansionary Federal Reserve policy, manifested in a series of favorable monetary policy shocks, worked to help insulate the US economy from the full effects of the other disturbances.

The string of adverse preference and technology shocks continued, however, throughout 2008 and into 2009. Moreover, these shocks grew larger in magnitude, adding substantially not just to the length but also to the severity of the great recession. The pattern of shocks generating the most recent recession also departed from patterns from the previous downturns in late 2008 and 2009, when according to panel $\mathrm{C}$ of table 3, monetary policy turned from being mildly expansionary to highly restrictive. These monetary policy shocks resulted, of course, from the zero lower bound on the short-term nominal interest rate, which became binding during the great recession but not during the two shorter and milder recessions that preceded it. In particular, the zero lower bound prevented the Federal Reserve from lowering interest rates in response to declining inflation and output in accordance with the estimated Taylor rule.

To isolate the effects of the zero lower bound during the great recession, figure 5 compares the actual paths for output and the short-term nominal interest rate (shown by the dashed 
lines, for output again as percentage changes from the previous cyclical peak and for the interest rate in annualized terms) to counterfactuals (shown in similar terms by the solid lines) generated under an alternative scenario. Whereas, in figure 4, each of the four shocks is allowed to operate in isolation with the remaining three shut off, in figure 5 a single shock

- the monetary policy shock - is zeroed out while allowing the preference, cost-push, and technology shocks all operate on output and the interest rate as just they did historically.

The bottom panel of figure 5, therefore, reveals that if the Fed had not faced the binding constraint, it would have continued to follow the estimated Taylor rule by lowering the shortterm interest rate another 100 basis points during late 2008 and 2009. The top panel of figure 5 then indicates that had the Fed left room for this additional monetary policy easing - say by setting a target for inflation 100 basis points higher than its actual (though implicit) target - the US economy would have bottomed out in the first quarter of 2009 and been well on its way to recovery by the year's end.

\section{Conclusion}

Let's return full circle to the question posed at the outset: in terms of its macroeconomics, is the great recession of 2007-09 really that different from what came before? The results derived here from estimating and simulating a New Keynesian model provide the answer: partly yes and partly no.

These results suggest that to a large extent, the pattern of exogenous demand and supply disturbances that caused the great moderation to end and the great recession to begin was quite similar to the patterns generating each of the two previous downturns in 1990-91 and 2001. Compared to those from previous episodes, however, the series of adverse shocks hitting the US economy most recently lasted longer and became more intense, contributing both to the exceptional length and severity of the great recession.

The length and severity of the great recession then caused Federal Reserve policy to run 
up against the zero lower bound on the short-term nominal interest rate, a new problem that had not been encountered before. And so, whereas monetary policy worked according to the estimated model in late 2007 and early 2008 to help insulate the economy from the full effects of the adverse shocks, just as it did throughout the previous two recessions, it added to and prolonged the recession once constrained by the zero lower bound in late 2008 and 2009.

All of these results indicate that the basic New Keynesian model continues to serve as a reliable guide for business cycle analysis and monetary policy evaluation. It would be interesting, as a next step, to investigate how the implications of the small-scale model used here would compare to those generated by more elaborate models, especially those that build

on the New Keynesian framework, either following Bernanke, Gertler, and Gilchrist (1999) and Iacoviello (2005) among others by incorporating credit market frictions of the kind that have been popularly viewed as important in light of widespread distress in the financial sector during the great recession or following Belongia and Ireland (2010) by including explicit roles for bank reserves, currency, and bank deposits as alternative sources of liquidity and thereby expanding the channels of monetary policy transmission beyond the single, interest rate channel that is present here. Finally, the results derived here point to the need for a more complete and detailed assessment of monetary policymaking strategy in light of the problems caused by the zero lower bound on the short-term nominal interest rate during the most recent, great recession.

\section{$5 \quad$ References}

Belongia, Michael T. and Peter N. Ireland. "The Barnett Critique After Three Decades: A New Keynesian Analysis." Manuscript. Chestnut Hill: Boston College, March 2010.

Bernanke, Ben S., Mark Gertler, and Simon Gilchrist. "The Financial Accelerator in a Quantitative Business Cycle Framework." In John B. Taylor and Michael Woodford, 
Eds. Handbook of Macroeconomics. Amsterdam: Elsevier Science, 1999.

Blanchard, Olivier Jean and Charles M. Kahn. "The Solution of Linear Difference Models Under Rational Expectations." Econometrica 48 (July 1980): 1305-1311.

Boivin, Jean and Marc P. Giannoni. "Has Monetary Policy Become More Effective?" Review of Economics and Statistics 88 (August 2006): 445-462.

Calvo, Guillermo A. "Staggered Prices in a Utility-Maximizing Framework." Journal of Monetary Economics 12 (September 1983): 383-398.

Canova, Fabio. "What Explains the Great Moderation in the U.S.? A Structural Analysis." Journal of the European Economic Association 7 (June 2009): 697-721.

Clarida, Richard, Jordi Gali, and Mark Gertler. "The Science of Monetary Policy: A New Keynesian Perspective." Journal of Economic Literature 37 (December 1999): 1661-1707.

Clarida, Richard, Jordi Gali, and Mark Gertler. "Monetary Policy Rules and Macroeconomic Stability: Evidence and Some Theory." Quarterly Journal of Economics 115 (February 2000): 147-180.

Efron, Bradley and Robert J. Tibshirani. An Introduction to the Bootstrap. Boca Raton: Chapman and Hall/CRC Press, 1993.

Hamilton, James D. Time Series Analysis. Princeton: Princeton University Press, 1994.

Iacoviello, Matteo. "House Prices, Borrowing Constraints, and Monetary Policy in the Business Cycle." American Economic Review 95 (June 2005); 739-764.

Ireland, Peter N. "Technology Shocks in the New Keynesian Model." Review of Economics and Statistics 86 (November 2004): 923-936. 
Ireland, Peter N. "Changes in the Federal Reserve's Inflation Target: Causes and Conseqeunces." Journal of Money, Credit, and Banking 39 (December 2007): 1851-1882.

Justiniano, Alejandro and Giorgio E. Primiceri. "The Time-Varying Volatility of Macroeconomic Fluctuations." American Economic Review 98 (June 2008): 604-641.

King, Robert G., Charles I. Plosser, and Sergio T. Rebelo. "Production, Growth and Business Cycles: I. The Basic Neoclassical Model." Journal of Monetary Economics 21 (March-May 1988): 195-232.

Klein, Paul. "Using the Generalized Schur Form to Solve a Multivariate Linear Rational Expectations Model." Journal of Economic Dynamics and Control 24 (September 2000): 1405-1423.

Kohn, Robert and Craig F. Ansley. "Fixed Interval Estimation in State Space Models when Some of the Data are Missing or Aggregated." Biometrika 70 (December 1983): 683-688.

Lubik, Thomas A. and Frank Schorfheide. "Testing for Indeterminacy: An Application to U.S. Monetary Policy." American Economic Review 94 (March 2004): 190-217.

Rotemberg, Julio J. "Sticky Prices in the United States." Journal of Political Economy 90 (December 1982): 1187-1211.

Smets, Frank and Raf Wouters. "An Estimated Dynamic Stochastic General Equilibrium Model of the Euro Area." Journal of the European Economic Association 1 (September 2003): 1123-1175.

Taylor, John B. "Discretion Versus Policy Rules in Practice." Carnegie-Rochester Conference Series on Public Policy 39 (December 1993): 195-214. 
Table 1. Maximum Likelihood Estimates and Standard Errors

\begin{tabular}{ccc}
\hline \hline Parameter & Estimate & Standard Error \\
\hline$\gamma$ & 0.3904 & 0.1070 \\
$\alpha$ & 0.0000 & 0.0000 \\
$\rho_{\pi}$ & 0.4153 & 0.0695 \\
$\rho_{g}$ & 0.1270 & 0.0689 \\
$\rho_{a}$ & 0.9797 & 0.0150 \\
$\rho_{e}$ & 0.0000 & 0.0000 \\
$\sigma_{a}$ & 0.0868 & 0.0593 \\
$\sigma_{e}$ & 0.0017 & 0.0002 \\
$\sigma_{z}$ & 0.0095 & 0.0018 \\
$\sigma_{r}$ & 0.0014 & 0.0003 \\
\hline \hline
\end{tabular}


Table 2. Forecast Error Variance Decompositions

\begin{tabular}{|c|c|c|c|c|}
\hline \multicolumn{5}{|c|}{ A. Output Growth } \\
\hline & \multicolumn{4}{|c|}{ Percentage of Forecast Error Variance Due To } \\
\hline Quarters Ahead & Preference & Cost-Push & Technology & Monetary Policy \\
\hline 1 & 25.9 & 3.0 & 59.1 & 12.0 \\
\hline 4 & 22.3 & 2.7 & 64.2 & 10.8 \\
\hline 8 & 22.6 & 2.7 & 63.5 & 11.1 \\
\hline 12 & 22.7 & 2.8 & 63.4 & 11.1 \\
\hline 20 & 22.7 & 2.8 & 63.4 & 11.1 \\
\hline \multirow[t]{3}{*}{40} & 22.7 & 2.8 & 63.4 & 11.1 \\
\hline & \multicolumn{4}{|c|}{ B. Inflation } \\
\hline & \multicolumn{4}{|c|}{ Percentage of Forecast Error Variance Due To } \\
\hline Quarters Ahead & Preference & Cost-Push & Technology & Monetary Policy \\
\hline 1 & 29.7 & 26.1 & 17.3 & 26.8 \\
\hline 4 & 30.8 & 19.7 & 20.1 & 29.3 \\
\hline 8 & 30.5 & 19.5 & 20.4 & 29.6 \\
\hline 12 & 30.5 & 19.4 & 20.4 & 29.6 \\
\hline 20 & 30.7 & 19.4 & 20.4 & 29.5 \\
\hline \multirow[t]{3}{*}{40} & 31.0 & 19.3 & 20.3 & 29.4 \\
\hline & \multicolumn{4}{|c|}{ C. Short-Term Nominal Interest Rate } \\
\hline & \multicolumn{4}{|c|}{ Percentage of Forecast Error Variance Due To } \\
\hline Quarters Ahead & Preference & Cost-Push & Technology & Monetary Policy \\
\hline 1 & 54.5 & 8.5 & 2.2 & 34.8 \\
\hline 4 & 86.7 & 2.4 & 1.3 & 9.6 \\
\hline 8 & 93.7 & 1.1 & 0.7 & 4.5 \\
\hline 12 & 95.8 & 0.7 & 0.4 & 3.0 \\
\hline 20 & 97.2 & 0.5 & 0.3 & 2.0 \\
\hline 40 & 98.1 & 0.3 & 0.2 & 1.3 \\
\hline
\end{tabular}


Table 3. Full-Sample Estimates of Shocks During Recesssions

\begin{tabular}{|c|c|c|c|c|}
\hline \multicolumn{5}{|c|}{ A. 1990 - 1991 Recession } \\
\hline & Preference & Cost-Push & Technology & Monetary Policy \\
\hline & $\varepsilon_{a t}$ & $\varepsilon_{e t}$ & $\varepsilon_{z t}$ & $\varepsilon_{r t}$ \\
\hline 1990:3 & -0.0719 & -0.0005 & -0.0048 & -0.0011 \\
\hline 1990:4 & -0.1306 & -0.0000 & -0.0150 & +0.0000 \\
\hline 1991:1 & -0.0835 & +0.0017 & -0.0103 & -0.0029 \\
\hline 1991:2 & -0.0444 & -0.0009 & +0.0106 & -0.0016 \\
\hline 1991:3 & -0.0625 & +0.0009 & -0.0003 & -0.0008 \\
\hline 1991:4 & -0.1407 & +0.0000 & +0.0013 & -0.0015 \\
\hline 1992:1 & -0.0609 & -0.0008 & +0.0094 & -0.0017 \\
\hline 1992:2 & -0.0352 & +0.0004 & +0.0043 & -0.0010 \\
\hline 1992:3 & -0.0858 & -0.0011 & +0.0038 & -0.0013 \\
\hline
\end{tabular}

B. 2001 Recession

\begin{tabular}{ccccc}
\hline & Preference & Cost-Push & Technology & Monetary Policy \\
& $\varepsilon_{a t}$ & $\varepsilon_{e t}$ & $\varepsilon_{z t}$ & $\varepsilon_{r t}$ \\
\hline $2001: 1$ & -0.1721 & +0.0011 & -0.0148 & -0.0020 \\
$2001: 2$ & -0.0994 & +0.0001 & +0.0034 & -0.0031 \\
$2001: 3$ & -0.1892 & -0.0002 & -0.0041 & +0.0013 \\
$2001: 4$ & -0.1381 & -0.0009 & -0.0003 & -0.0014 \\
$2002: 1$ & -0.0066 & -0.0007 & +0.0040 & +0.0005 \\
$2002: 2$ & -0.0144 & +0.0000 & -0.0043 & +0.0009 \\
$2002: 3$ & -0.0133 & -0.0004 & -0.0040 & +0.0009 \\
$2002: 4$ & -0.0481 & +0.0003 & -0.0118 & +0.0003 \\
$2003: 1$ & -0.0360 & +0.0017 & -0.0072 & +0.0001 \\
\hline
\end{tabular}

\section{2007 - 2009 Recession}

Preference Cost-Push Technology Monetary Policy

\begin{tabular}{ccccc} 
& $\varepsilon_{a t}$ & $\varepsilon_{e t}$ & $\varepsilon_{z t}$ & $\varepsilon_{r t}$ \\
\hline $2007: 4$ & -0.1244 & +0.0004 & -0.0041 & -0.0019 \\
$2008: 1$ & -0.1891 & -0.0014 & -0.0059 & -0.0019 \\
$2008: 2$ & -0.0347 & -0.0015 & -0.0040 & -0.0001 \\
$2008: 3$ & -0.0532 & +0.0033 & -0.0212 & -0.0002 \\
$2008: 4$ & -0.2890 & -0.0032 & -0.0114 & +0.0023 \\
$2009: 1$ & -0.0451 & +0.0022 & -0.0192 & +0.0031 \\
$2009: 2$ & -0.0296 & -0.0006 & +0.0046 & +0.0036 \\
$2009: 3$ & +0.0041 & +0.0004 & +0.0023 & +0.0024 \\
$2009: 4$ & +0.0282 & -0.0006 & +0.0089 & +0.0010 \\
\hline
\end{tabular}

D. Estimated Standard Deviations

Preference Cost-Push Technology Monetary Policy

$\begin{array}{cccc}\sigma_{a} & \sigma_{e} & \sigma_{z} & \sigma_{r}\end{array}$

$\begin{array}{llll}0.0868 & 0.0017 & 0.0095 & 0.0014\end{array}$



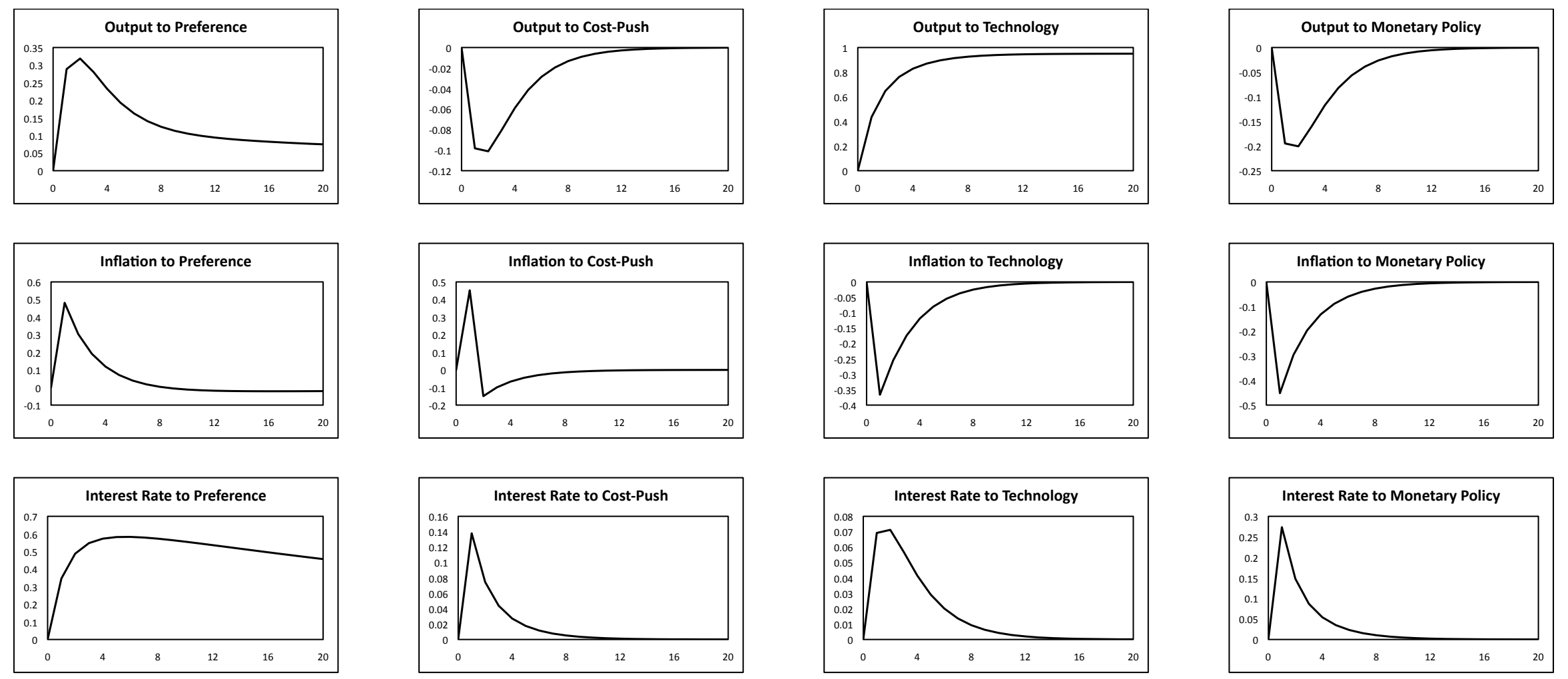

Figure 1. Impulse Responses. Each panel shows the percentage-point response in one of the model's endogenous variables to a one-standard deviation innovation in one of the model's exogenous shocks. Output is expressed in levels; the inflation and interest rates are in annualized terms. 

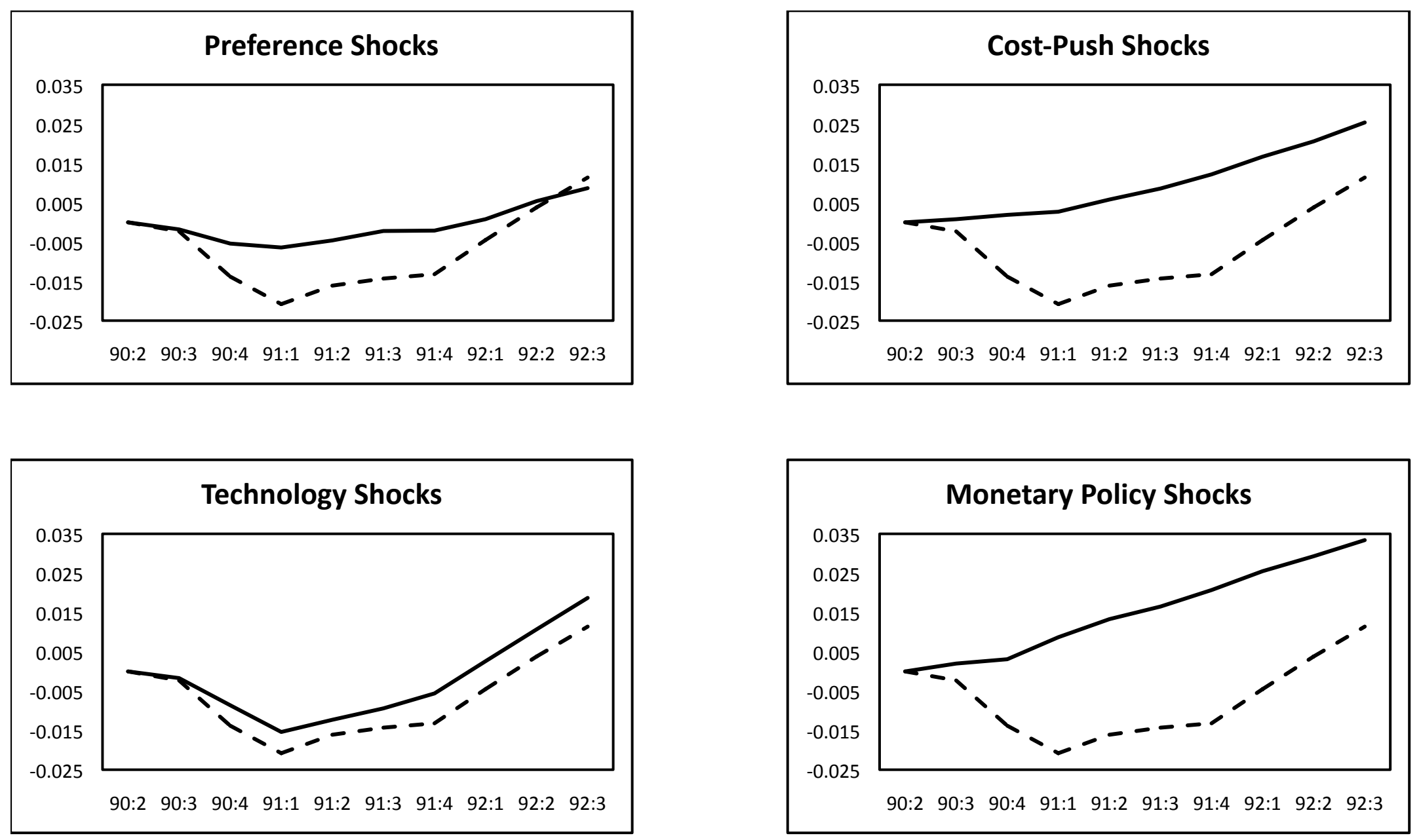

Figure 2. Counterfactual Output Paths: 1990-1991 Recession. Each panel compares the actual path for output (dashed line) to the counterfactual path (solid line) when changes in output are driven by the single shock indicated. Both the actual and counterfactual output paths are expressed as percentage deviations from the level achieved at the cyclical peak just prior to the onset of the recession. 

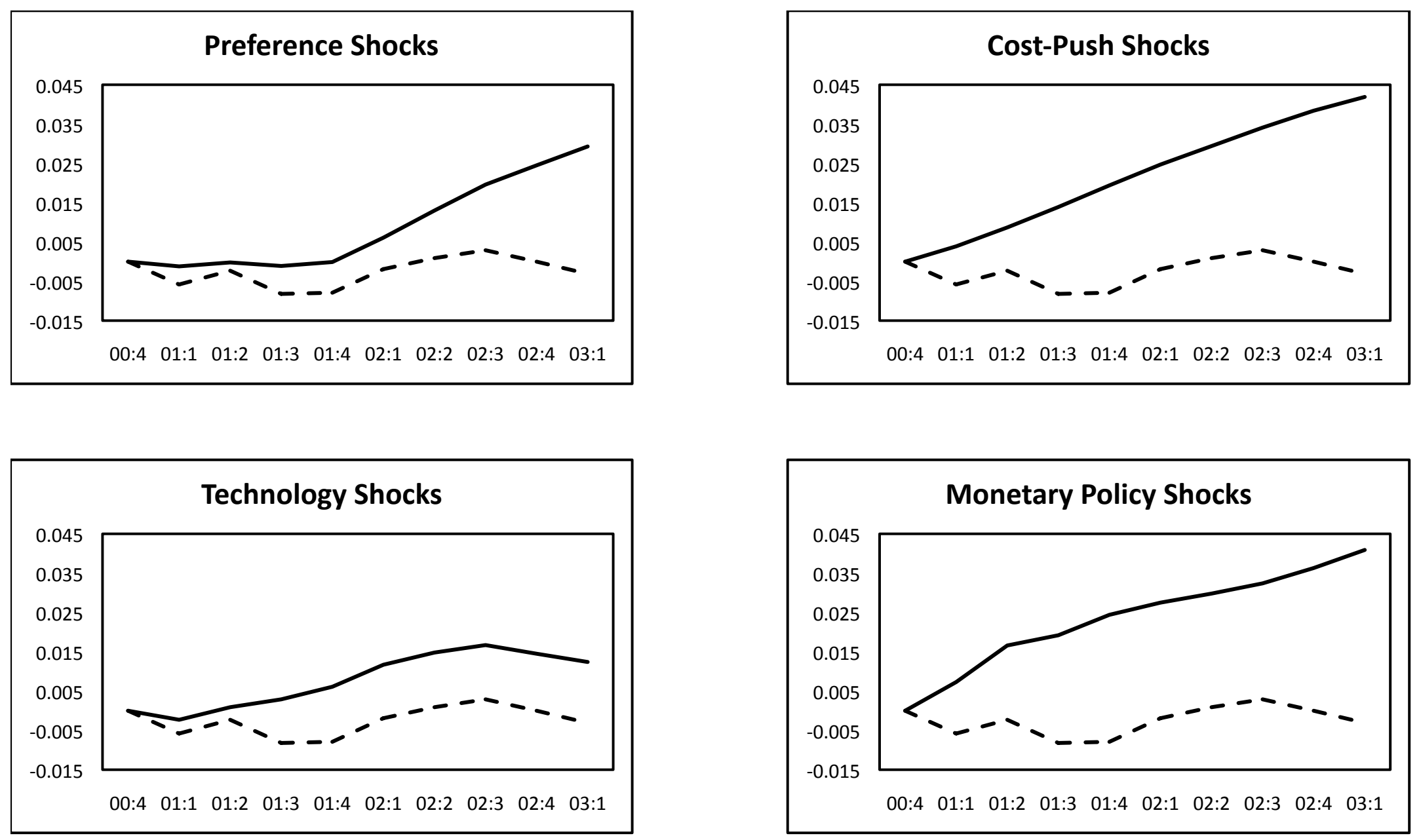

Figure 3. Counterfactual Output Paths: 2001 Recession. Each panel compares the actual path for output (dashed line) to the counterfactual path (solid line) when changes in output are driven by the single shock indicated. Both the actual and counterfactual output paths are expressed as percentage deviations from the level achieved at the cyclical peak just prior to the onset of the recession. 

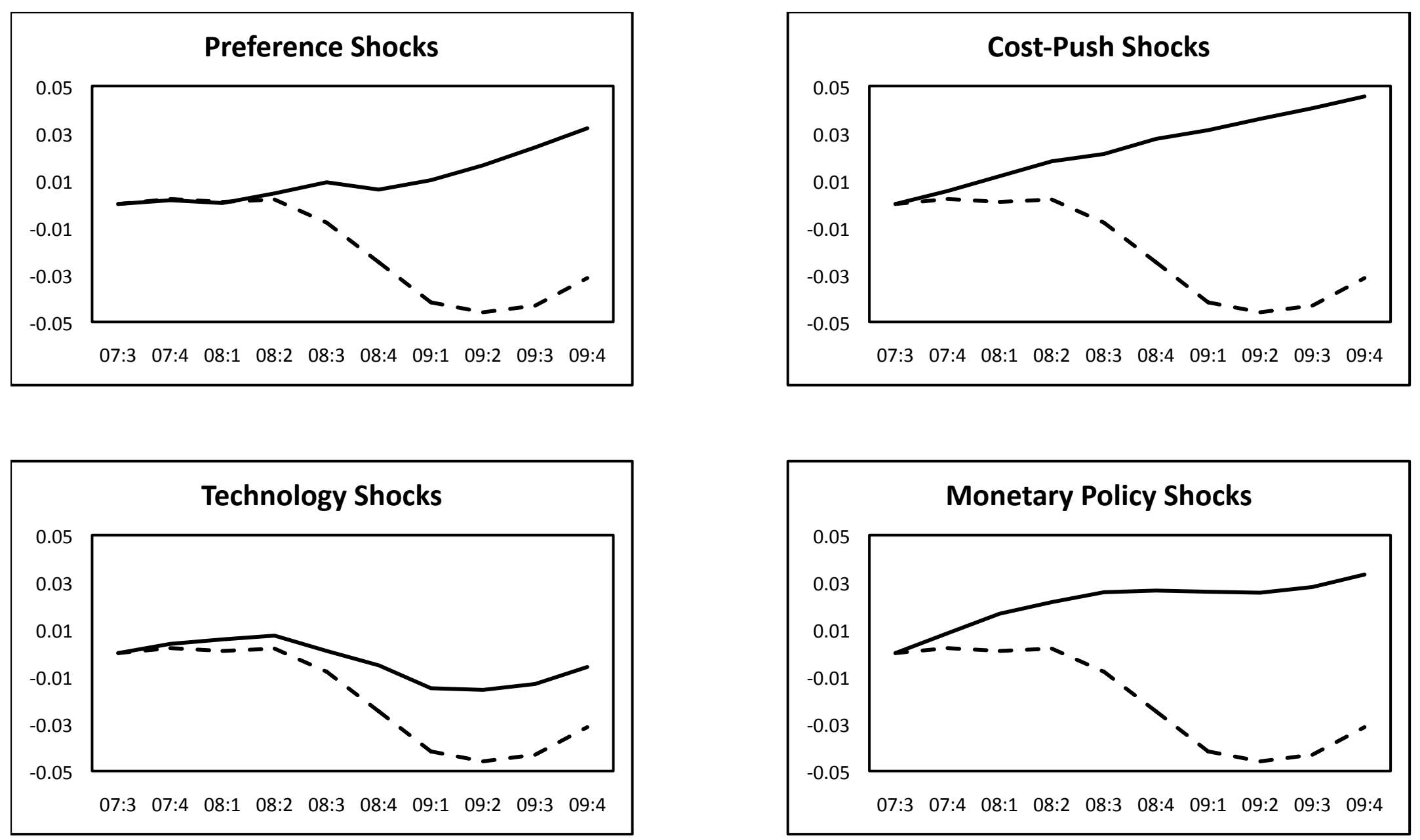

Figure 4. Counterfactual Output Paths: 2007-2009 Recession. Each panel compares the actual path for output (dashed line) to the counterfactual path (solid line) when changes in output are driven by the single shock indicated. Both the actual and counterfactual output paths are expressed as percentage deviations from the level achieved at the cyclical peak just prior to the onset of the recession. 

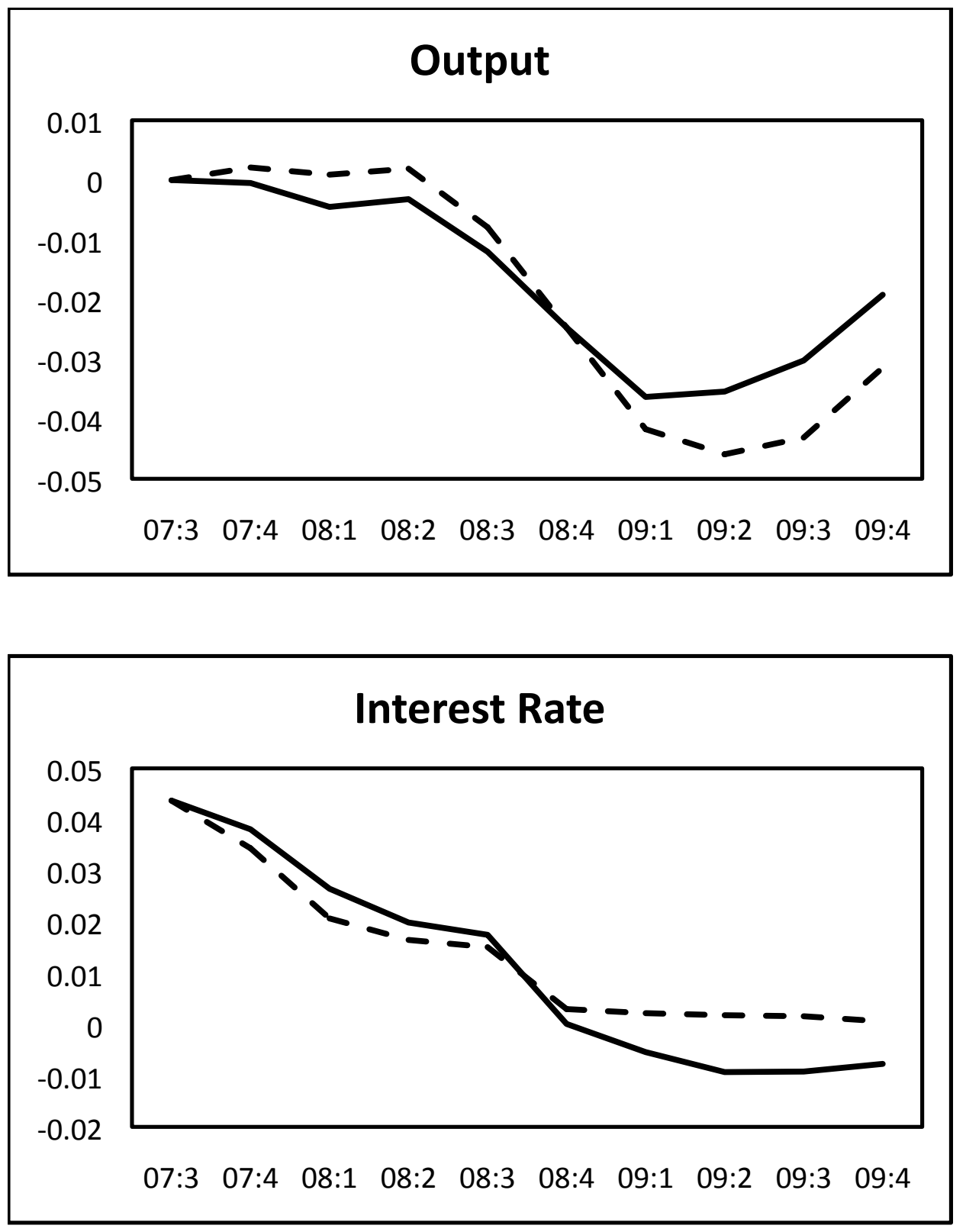

Figure 5. Counterfactual Output and Interest Rate Paths: 2007-2009 Recession. Each panel compares the actual path (dashed line) for output or the interest rate to the counterfactual path (solid line) when no monetary policy shocks occur. Output is expressed as a percentage deviation from the level achieved at the previous cyclical peak. The interest rate is expressed in annualized terms. 